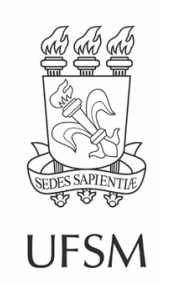

\title{
Artigos
}

\section{Fitossociologia e diversidade em fragmentos florestais com diferentes históricos de intervenção na Amazônia Ocidental}

\author{
Phytosociology and diversity in forest fragments with different \\ intervention historics in the Western Amazon
}

\author{
Simone Pereira da Silva ${ }^{~} \bullet$, Evandro José Linhares Ferreira $" \odot$, \\ Lucélia Rodrigues Santos "II॰ \\ ' Pesquisadora Autônoma, São Paulo, SP, Brasil \\ " Instituto Nacional de Pesquisas da Amazônia, Rio Branco, AC, Brasil \\ III Universidade Paulista, Rio Branco, AC, Brasil
}

\section{RESUMO}

Neste estudo buscou-se realizar a caracterização florística e estrutural de três fragmentos florestais que sofreram intervenção antrópica, em intervalos de tempo distintos, localizados na Área de Proteção Ambiental Lago do Amapá em Rio Branco - AC, Brasil. O Fragmento I possui histórico de intervenção para formação de pastagem e exploração madeireira na década de 1960, o Fragmento II, histórico de intervenção de corte/queima e plantio na década de 1970 e o Fragmento III, histórico de intervenção para formação de pastagem na década de 1980. Para a amostragem florística e fitossociológica foram alocadas duas parcelas por fragmento medindo 0,5 hectares cada (20 m x $250 \mathrm{~m}$ ), totalizado uma área de três hectares. Todos os indivíduos arbóreos com DAP $\geq 10 \mathrm{~cm}$ foram inventariados. Calcularam-se os parâmetros fitossociológicos como dominância, densidade, frequência, Valor de Importância (VI) e área basal. A diversidade entre fragmentos foi obtida através do índice de Shannon-Weaver ( $\left.\mathrm{H}^{\prime}\right)$ e a similaridade pelo índice de Jaccard. As comparações de médias foram realizadas por meio do Teste de Tukey com 5\% de significância. Ao todo foram inventariados 1427 indivíduos, distribuídos em 44 famílias e 193 espécies. Os índices de diversidade $\mathrm{H}^{\prime}$ encontrados foram: 4,21 nats.indivíduos-1 para o Fragmento I, 3,74 nats.indivíduos ${ }^{-1}$ para o Fragmento II e 3,50 nats.indivíduos ${ }^{-1}$ para o Fragmento III. O índice de Jaccard apontou maior similaridade entre os Fragmentos II e III. O Fragmento I diferiu estatisticamente dos demais com relação à área basal, número de gêneros e de espécies. $O$ estrato médio (classe de altura de $8 \mathrm{~m} \leq \mathrm{h}<16,93 \mathrm{~m}$ ) apresentou o maior número de indivíduos. Com relação às classes diamétricas, observou-se maior quantidade de indivíduos nas primeiras classes, seguindo o padrão J invertido em todos os fragmentos. O resultado do estudo apontou que o fragmento com histórico de antropização mais antigo possui estrutura, riqueza e diversidade de espécies distintas dos demais fragmentos.

Palavras-chave: Sucessão secundária; Estrutura; Fragmentação 


\section{ABSTRACT}

In this study, we sought to carry out the floristic and structural characterization of three forest fragments that underwent anthropic intervention, at different time intervals, located in the Environmental Protection Area 'Lago do Amapá' in Rio Branco, state of Acre, Brazil. Fragment I has a history of intervention for the formation of pasture and timber extraction in the 1960s. Fragment II has a history of intervention for cutting/burning and planting in the 1970s and Fragment III has a history of intervention for the formation of pastures in the 1980s. For floristic and phytosociological sampling, two plots per fragment measuring 0.5 hectares each $(20 \mathrm{~m} \times 250 \mathrm{~m})$ were allocated, totaling an area of three ha. All arboreal individuals with $\mathrm{DBH} \geq 10 \mathrm{~cm}$ were inventoried. Phytosociological parameters such as dominance, density, frequency, Importance Value (IV) and basal area were calculated. The diversity between fragments was obtained using the Shannon-Weaver index $\left(\mathrm{H}^{\prime}\right)$ and similarity using the Jaccard index. The comparisons of means were performed using the Tukey test with $5 \%$ significance. Altogether, 1,427 individuals were inventoried, distributed in 44 families and 193 species. The H' diversity indices found were: 4.21 for Fragment I, 3.74 for Fragment II and 3.50 for Fragment III. The Jaccard index showed a greater similarity between fragments II and III. Fragment I differed statistically from the others in relation to the basal area, number of genera and species. The medium strata (height class $8 \leq h<16.93$ ) had the largest number of individuals. Regarding the diametric classes, a greater number of first-class individuals was observed, following the inverted J pattern in all fragments. The result of the study pointed out that the fragment with the oldest history of anthropization has structure, richness and diversity of species distinct from the other fragments.

Keywords: Secondary succession; Structure; Fragmentation

\section{INTRODUÇÃO}

A Amazônia Brasileira se estende por aproximadamente 6,4 milhões de hectares, abrigando uma vasta biodiversidade, no entanto, a fragmentação pode alterar facilmente o equilíbrio ecológico existente, ameaçando a diversidade de espécies (VERÍSSIMO et al., 2011; OLIVEIRA; AMARAL, 2005). Estima-se que na Amazônia Legal entre os períodos de 2011 a 2013 foram degradados 38.718 km² (INSTITUTO DE PESQUISAS ESPACIAIS, 2019). O principal agente de conversão da cobertura florestal e da fragmentação de habitat são as ações antrópicas, tornando necessária a elaboração de medidas conciliatórias de conservação e uso econômico (GOMES; GONÇALVES; SANTOS, 2010). Araújo (2016) cita como uma das principais causas de remoção da vegetação nativa a expansão urbana, que é responsável pelo surgimento de fragmentos florestais rodeados por uma matriz antropizada. A vegetação secundária corresponde 
às formações decorrentes de processos naturais de sucessão, após supressão total ou parcial originado de causas antrópicas (PRADO; MALLMANN; PEREIRA FILHO, 2015).

Conhecer a diversidade e estrutura de florestas fragmentadas é essencial para o acompanhamento da regeneração e entendimento das relações entre espécies e o meio, servindo de base para a elaboração de planos de preservação e conservação (SOUZA; APARÍCIO, 2018). Bianchin e Bellé (2013) postulam que a fitossociologia é a ferramenta de estudo das inter-relações de espécies vegetais que formam uma comunidade, dados fornecidos com essas análises auxiliam na tomada de decisão visando a uma boa gestão dessas áreas.

O estado do Acre conta com 22 Unidades de Conservação, como Áreas de Proteção Ambiental (APAs), Florestas Nacionais, Florestas Estaduais, Estações Ecológicas, Parques Estaduais e Áreas de Relevante Interesse Ecológico. Fora da classificação de Unidade de Conservação, mas igualmente protegidas, somam-se ainda 36 Terras Indígenas (TIs) (ACRE, 2010). A Área de Proteção Ambiental Lago do Amapá é uma das APAs do município de Rio Branco, devido ao avanço da área urbana, atividades como extração de areia, criação de bovinos e implantação de pequenas plantações, encontra-se extremamente fragmentada e sob constante pressão antrópica (ACRE, 2005).

Considerando o contexto, o objetivo deste estudo foi avaliar e caracterizar a composição florística e estrutural de três fragmentos de floresta secundária com históricos diferentes de antropização na Área de Proteção Ambiental Lago do Amapá.

\section{MATERIAL E MÉTODOS}

\section{1 Área de estudo}

O estudo foi realizado na Área de Proteção Ambiental Lago do Amapá. A APA possui aproximadamente 5.208 hectares e está localizada a $12 \mathrm{~km}$ do centro da cidade de Rio Branco no estado do Acre, sob as coordenadas $10^{\circ} 00^{\prime} 00^{\prime \prime}-10^{\circ} 04^{\prime} 30^{\prime \prime}$ S e 67²52'30"- 
$67^{\circ} 48^{\prime} 00^{\prime \prime}$ W. A vegetação local encontra-se extremamente fragmentada (Figura 1), predominando a tipologia florestal 'Floresta Aberta com Palmeiras' (ACRE, 2010) e faz parte da bacia do Rio Acre e de seu afluente o Riozinho do Rola. Os corpos d'água ao alternarem os períodos de vazante e cheia de acordo com as chuvas amazônicas promovem o desbarrancamento de suas margens, o que deu origem ao Lago do Amapá, o qual conta com aproximadamente 6 km de extensão.

Figura 1 - Imagem da Área de Proteção Ambiental Lago do Amapá, Rio Branco - AC, destacada em amarelo com localização dos três fragmentos analisados

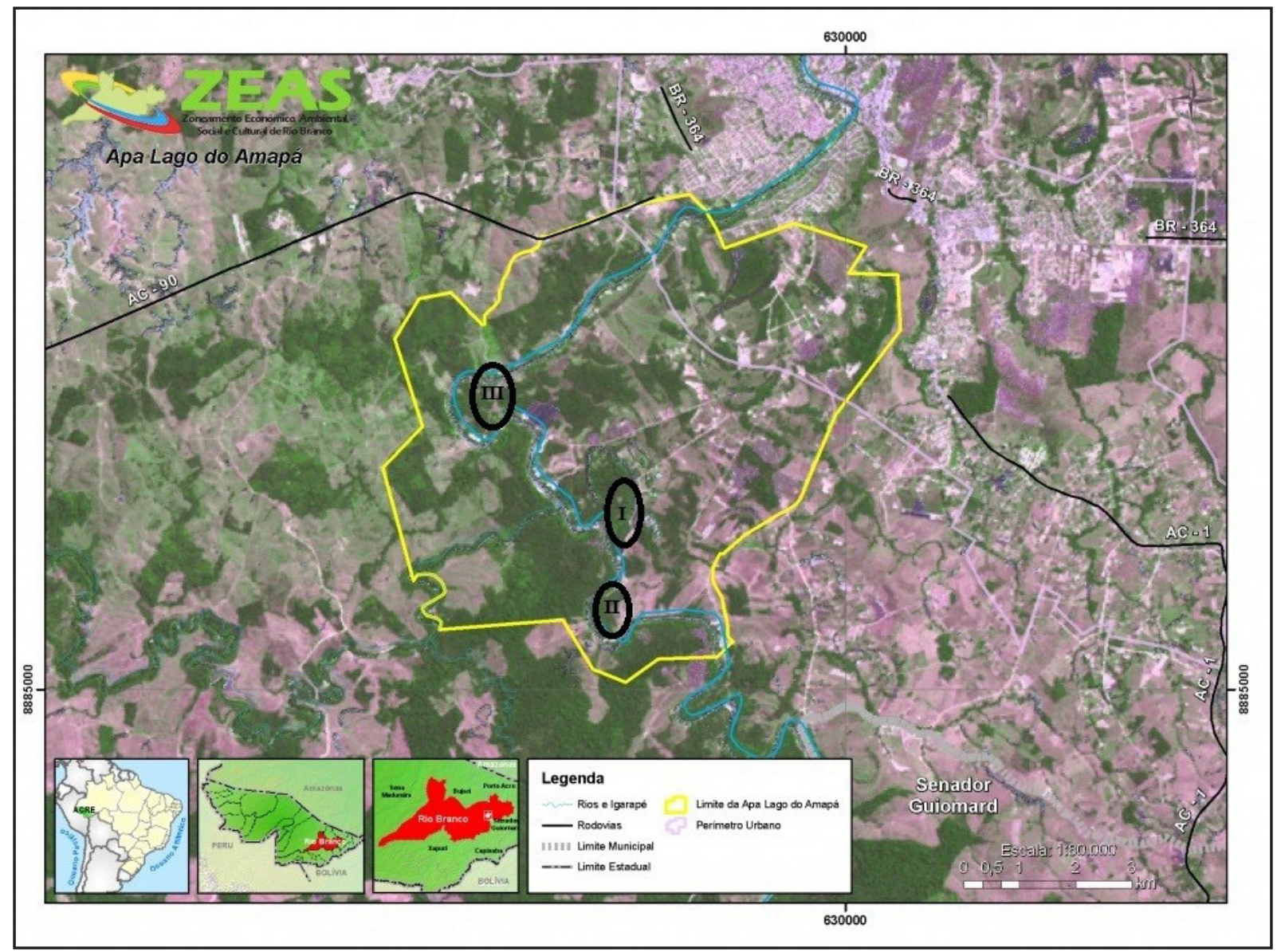

Fonte: Adaptada de Acre (2005)

Escala: 1:80 000

O solo é do tipo Luvissolo hipocrômico, o clima é o tropical úmido Am segundo a classificação de Köppen-Geiger, com temperaturas variando de $24,5^{\circ} \mathrm{C}$ a $32^{\circ} \mathrm{C}$, o regime pluviométrico anual varia entre 1.877 mm e 1.982 mm (ACRE, 2010). 
O Fragmento I (Figura 2) está localizado no “Ramal do Gurgel" (1003'17'. 28"S-1004'9.12"S e 6750'50.12"W-6750'31.2"W; altitude de $144 \mathrm{~m}$ ), possui área estimada em 21,00 ha. O proprietário atual reside na área desde 1962 e segundo o mesmo desde sua chegada não houve alteração substancial da vegetação, a intervenção no passado se deu por meio de formação de pastagem e exploração madeireira. Registra-se a presença de árvores de grande porte (como Cedrela odorata, Swietenia macrophylla e Clarisia racemosa). No entorno do fragmento existe uma estação de piscicultura (Figura 2a), áreas de pastagem cultivada (Figura 2b) e uma pequena área de floresta em estágio inicial de sucessão (Figura 2c).

Figura 2 - Fragmento I selecionado para o estudo na APA Lago do Amapá, Rio Branco, Acre. Destacando a área do fragmento em amarelo e a área amostrada em vermelho. Estação de piscicultura (a); Área de pastagens (b) e Floresta em estágio inicial de sucessão (c)

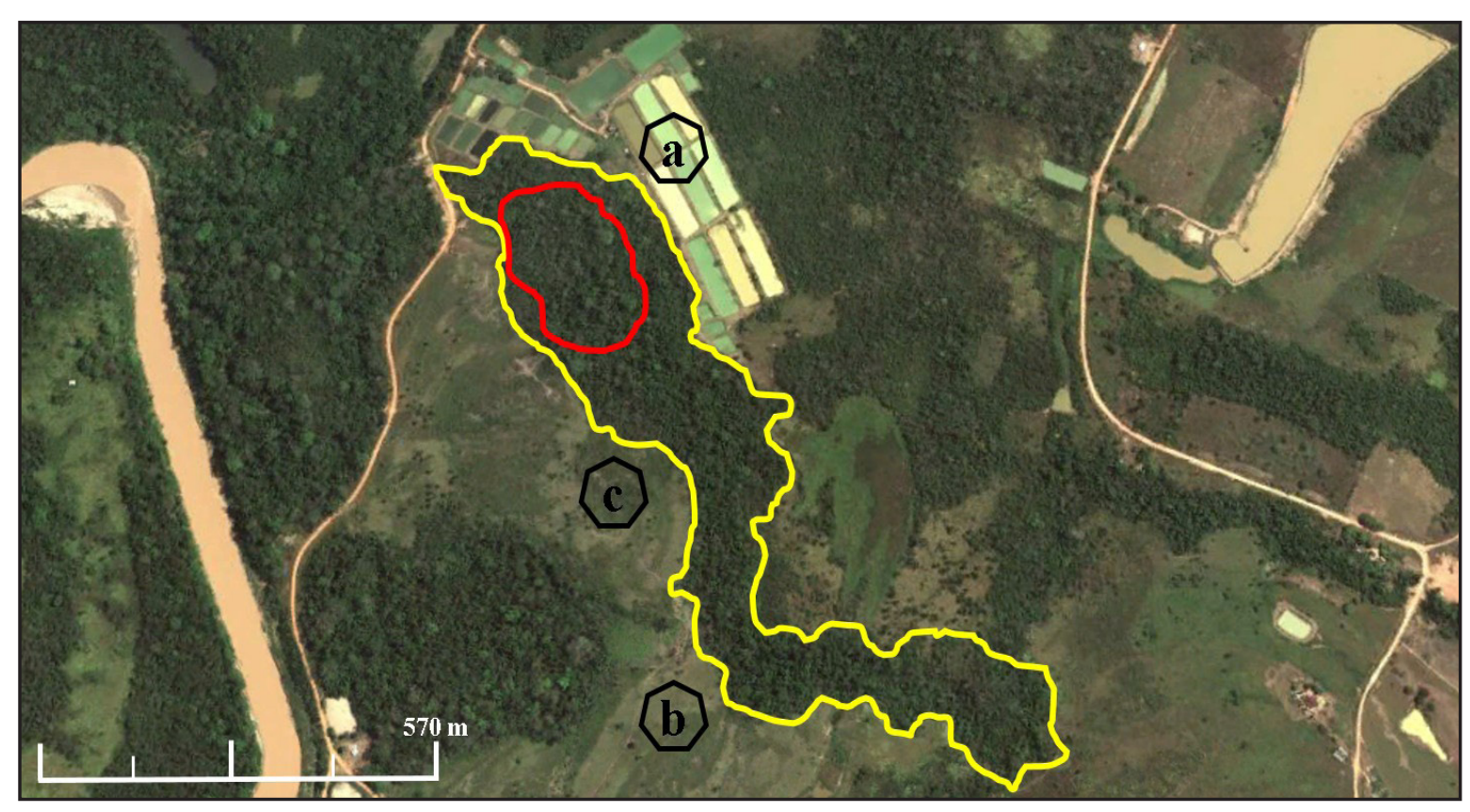

Fonte: Autores (2019)

O Fragmento II (Figura 3) está localizado na altura do km quatro do "Ramal do Ozório" (1001'59.52"S 1002'25.44"S-6752'14.88"W-6751'48.96" W; altitude 142 
m), apresenta um área aproximada de 53,25 ha e foi desmatado em ciclos de corte/ queima/plantio/abandono que duraram até 1970. A partir dessa época, a interferência diminuiu. Segundo o atual proprietário, em 1983 toda a área já estava em estágio de sucessão avançada, apresentando grande quantidade de indivíduos com maior área basal (Figura 3).

Figura 3 - Fragmento II selecionado para o estudo na APA Lago do Amapá, Rio Branco, Acre. Destacando a área do fragmento (em amarelo) e a área amostrada (em vermelho). Área para cultivo de agricultura de subsistência (a)

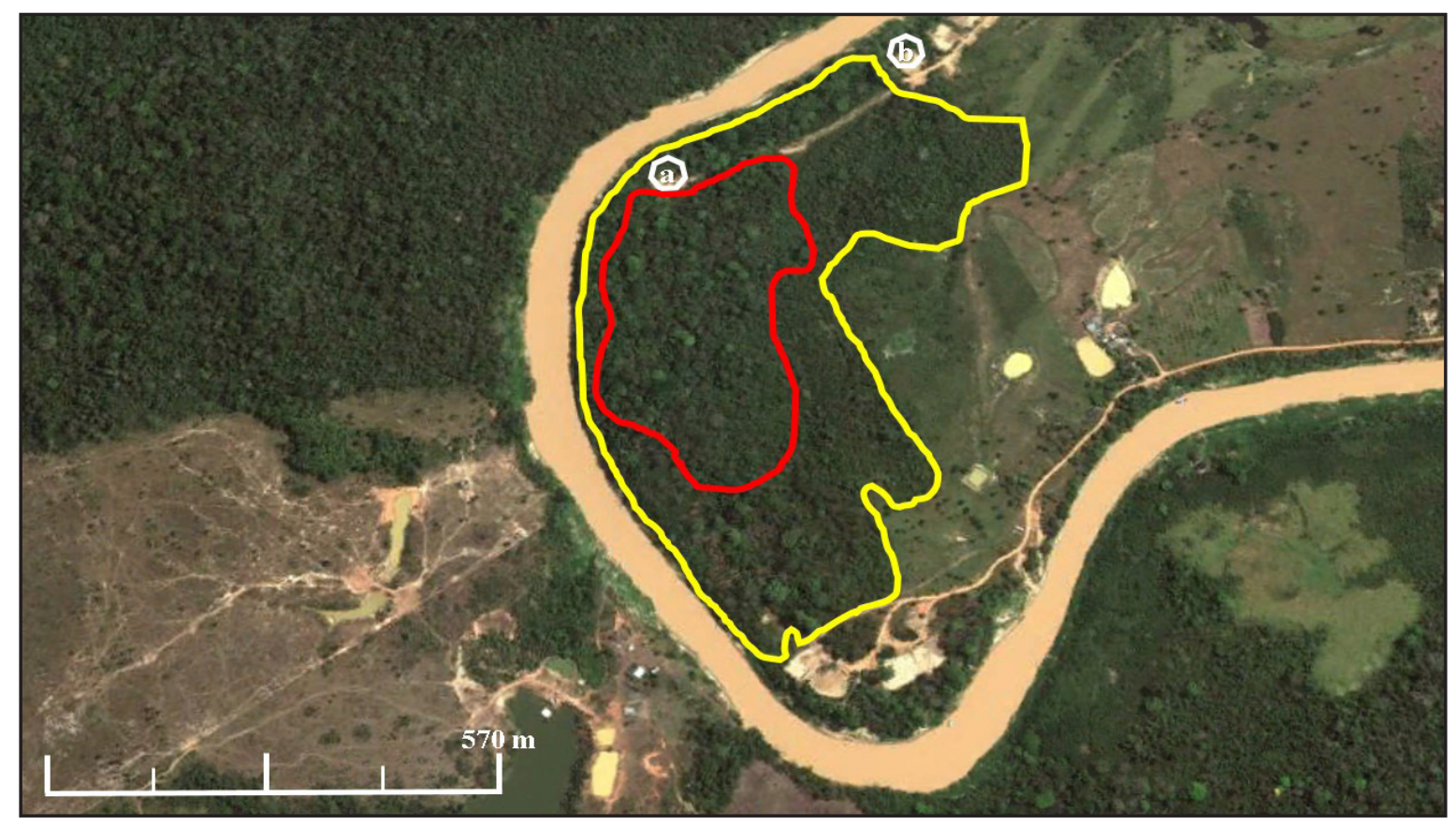

Fonte: Autores (2019)

O Fragmento III (Figura 4) está localizado no final do "Ramal do Gurgel", às

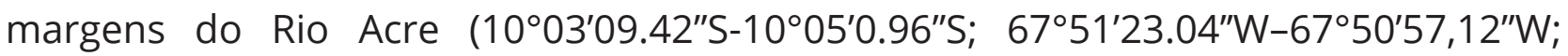
altitude de $147 \mathrm{~m}$ ), apresenta uma área de 31,30 ha. Toda a vegetação deste local foi suprimida por volta de 1979 para o estabelecimento de uma área de pastagem, sendo preservada apenas a faixa de vegetação próxima ao Rio Acre. Por volta de 1984, a área foi abandonada e desde então se encontra em processo de regeneração natural. 
Figura 4 - Fragmento III selecionado para o estudo na APA Lago do Amapá, Rio Branco, Acre. Destacando a área do fragmento (em amarelo) e a área amostrada (em vermelho). Áreas de deposição de areia lavada (a) e (b)

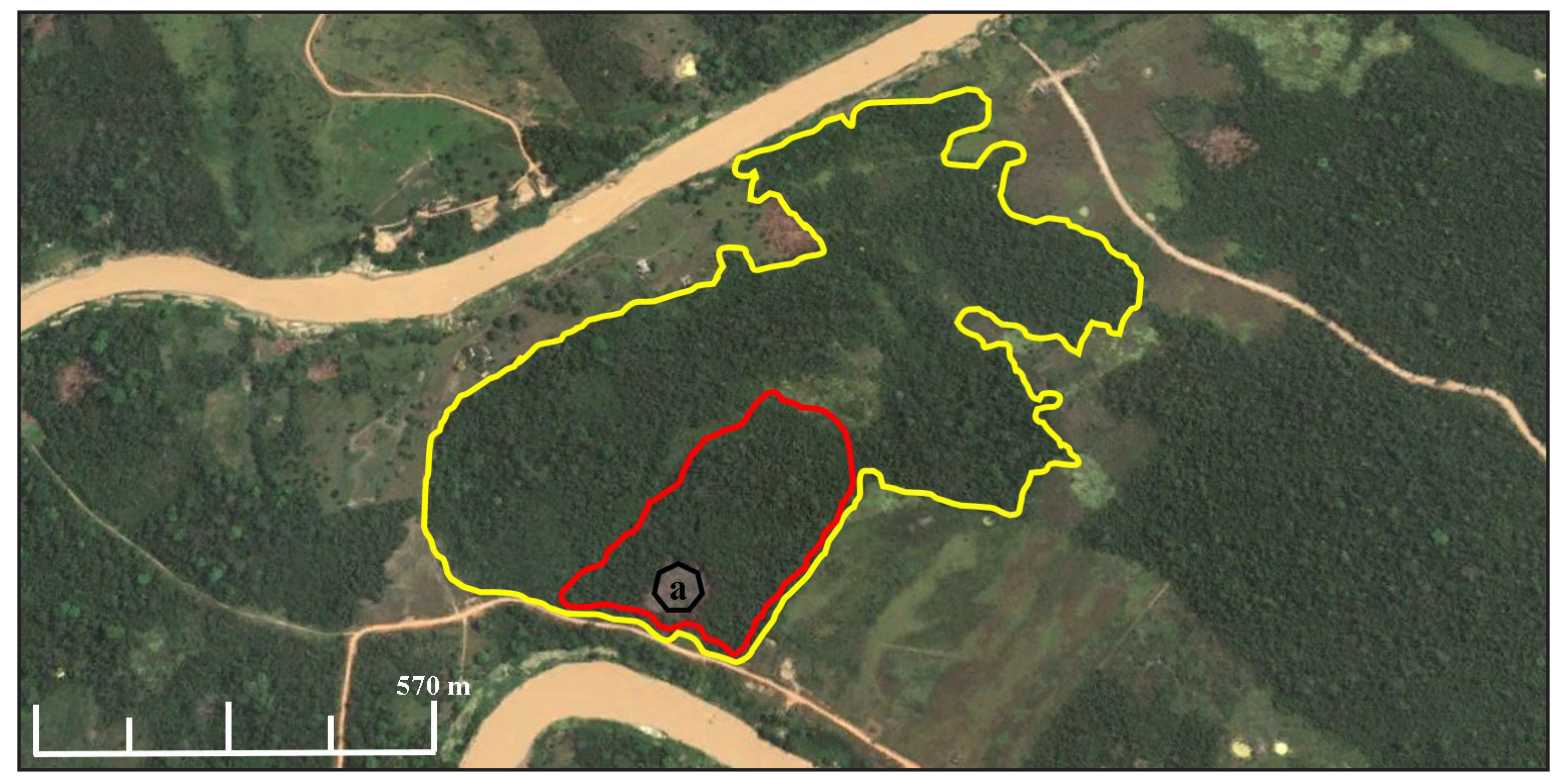

Fonte: Autores (2019)

\subsection{Amostragem, coleta e análise de dados}

A coleta de dados foi realizada entre os anos de 2009 e 2010, em cada fragmento foram alocadas duas parcelas retangulares medindo $20 \mathrm{~m}$ x $250 \mathrm{~m}(0,5 \mathrm{ha})$, totalizando 1 ha por fragmento. A localização das parcelas foi determinada de acordo com as condições logísticas locais, os tamanhos e formas variáveis dos fragmentos e a necessidade de aquiescência dos proprietários rurais para a realização do estudo.

Foram medidos com fita dendrométrica todos os indivíduos arbóreos com DAP $\geq 10 \mathrm{~cm}$ (MOURA; ROSSELL; MASCARENHAS, 2017) e a altura foi estimada com o auxílio de vara de referência. Todos os indivíduos foram marcados com etiqueta de alumínio e identificados por especialista em campo. Posteriormente, foi efetuada a confirmação da nomenclatura botânica por meio de consulta ao material do acervo do Herbário do Parque Zoobotânico da Universidade Federal do Acre e da lista de espécies do Herbário do The New York Botanical Garden (EUA). As espécies foram classificadas pelo sistema Angiosperm Phylogeny Group (2009). 
Para análise da composição florística em cada fragmento foram empregados os índices de diversidade de Shannon-Weaver $\left(\mathrm{H}^{\prime}\right)$ e o Índice de Similaridade Jaccard (SJ) (GONÇALVES; SANTOS, 2008). Para a análise da estrutura da vegetação, os parâmetros fitossociológicos foram: Densidade absoluta (DA), Densidade relativa (DR), Frequência absoluta (FA), Frequência relativa (FR), Dominância absoluta (DoA), Dominância relativa (DoR), Índice de Valor de Importância (IVI). Para análise da estrutura vertical, os estratos foram definidos de acordo com o proposto por Souza e Leite (1993).

Os parâmetros estruturais da vegetação e a composição florística das espécies foram calculados utilizando o software Mata Nativa versão 2.0 (SOUZA, 2006). A similaridade florística entre as áreas amostradas foi verificada com o auxílio do programa Biodiversity Pro, utilizando o coeficiente de similaridade de Jaccard (SJ). A tabulação dos dados foi feita no software Microsoft Office Excel® 2007. Para a comparação de médias referentes aos índices de Shannon-Weaver, número de indivíduos por hectare e área basal foi utilizado o programa Assistat 7.7 Beta.

\section{RESULTADOS E DISCUSSÃO}

O levantamento florístico realizado nos três fragmentos registrou 1497 indivíduos distribuídos em 193 espécies, 137 gêneros e 44 famílias botânicas. Das 193 espécies, 67 foram identificadas apenas pelo gênero, e uma pela família.

As famílias com maior número de indivíduos foram: Fabaceae (256 indivíduos), Anacardiaceae (154 indivíduos), Arecaceae (131 indivíduos), Euphorbiaceae (91 indivíduos), Boraginaceae (71 indivíduos) e Rubiaceae (63 indivíduos). As famílias com maior número de espécies foram Fabaceae (51 espécies), Euphorbiaceae (22 espécies), Malvaceae (17 espécies) e Annonaceae (15 espécies).

Na Amazônia, a família Fabaceae é citada como uma das mais importantes em diversos estudos fitossociológicos (CARIM et al., 2013; CONDÉ; TONINI, 2013; TER STEEGE et al., 2013; SILVA et al., 2014; AMARAL; VIEIRA; ALMEIDA, 2016; DIONÍSIO et al., 2016; SOUSA; APARÍCIO, 2018). Mesmo em outros biomas é comum observar a 
família Fabaceae entre as mais representativas. A expressiva frequência dessa família é atribuída ao elevado número de espécies que possui, de acordo com Lima et al. (2019), no Brasil foram registradas 2.735 espécies e 212 gêneros, com significativa abundância em quase todos os biomas. Anacardiaceae e Arecaceae apesar de se destacarem pelo grande número de indivíduos apresentaram apenas 3 e 6 espécies, respectivamente, sendo frequente a ocorrência de Spondias mombin (Anacardiaceae) e Attalea phalerata (Arecaceae).

Com relação à distribuição horizontal e diversidade, o Fragmento I apresentou maior número de indivíduos, área basal e também maior riqueza e divesidade específicas (Tabela 1). Sendo o fragmento com histórico de intervenção mais antigo entre os analisados, este concentra a maior parte de indivíduos de grande porte, por estar em um estágio avançado de regeneração sua estrutura já apresenta característcas de uma floresta madura como uma quantidade mais elevada de árvores com áreas basais maiores (PARTHANSARATHY, 1999; NUNES et al., 2003). O número de indivíduos por hectare do Fragmento I não diferiu estatisticamente do Fragmento II. O fato de que o Fragmento III apresenta um histórico de intervenção mais recente e possui menor número de indivíduos registrados com relação aos demais fragmentos, exerceu influência sobre a diversidade de famílias, gêneros e espécies.

Tabela 1 - Valores das médias de área basal, número de indivídos por hectare, famílias, gêneros, espécies e índice de Shannon-Wiener, para cada fragmento amostrado na APA Lago do Amapá, Rio Branco - AC

\begin{tabular}{lcccccc}
\hline Fragmento & $\mathbf{A B}\left(\mathbf{m}^{\mathbf{2}} / \mathbf{h a}\right)$ & Indivíduos/ha & Famílias & Gêneros & Espécies & $\mathbf{H}^{\prime}$ \\
\hline $\mathrm{I}$ & $25,016 \mathrm{a}$ & $619 \mathrm{a}$ & 36 & 104 & 130 & $4,21 \mathrm{a}$ \\
$\mathrm{II}$ & $17,18 \mathrm{~b}$ & $519 \mathrm{a}$ & 31 & 82 & 97 & $3,74 \mathrm{~b}$ \\
III & $17,178 \mathrm{~b}$ & $289 \mathrm{~b}$ & 21 & 46 & 62 & $3,5 \mathrm{~b}$ \\
\hline
\end{tabular}

Fonte: Autores (2019)

Em que: $\mathrm{AB}$ = área basal, Indivíduos/ha = número de indivíduos por hectare, $\mathrm{H}^{\prime}$ = índice de ShannonWiener. Médias na mesma coluna com letras distintas diferem entre si a $5 \%$ de probabilidade de erro pelo teste de Tukey. 
Os índices de diversidade de Shannon-Weaver obtidos neste estudo estão próximos aos encontrados em outros trabalhos na Amazônia. Silva et al. (2014) analisando a diversidade de uma floresta de terra firme no Amapá registraram um índice de 4,27 nats.indivíduos ${ }^{-1}$. Andrade et al. (2015) encontraram índices variando de 4,44 nats.indivíduos ${ }^{-1}$ a 4,47 nat.indivíduos ${ }^{-1}$ em dois fragmentos de floresta tropical densa no Pará. Condé e Tonini (2013) ao analisarem a diversidade de uma Floresta Ombrófila Densa em Roraima registraram um $\mathrm{H}^{\prime}=3,27$ nats.indivíduos ${ }^{-1}$. Os menores valores para este parâmetro observados no presente estudo foram para os fragmentos com históricos de antropização mais recente, no entanto, ainda estão dentro do esperado para a região. O índice de similaridade de Jaccard (Figura 5) indicou uma variação de $27 \%$ a $29 \%$ entre a composição de espécies nos três fragmentos avaliados.

Figura 5 - Dendrograma de similaridade florística obtido pelo índice Jaccard nos Fragmentos I, II e III analisados na APA Lago do Amapá, Rio Branco - AC

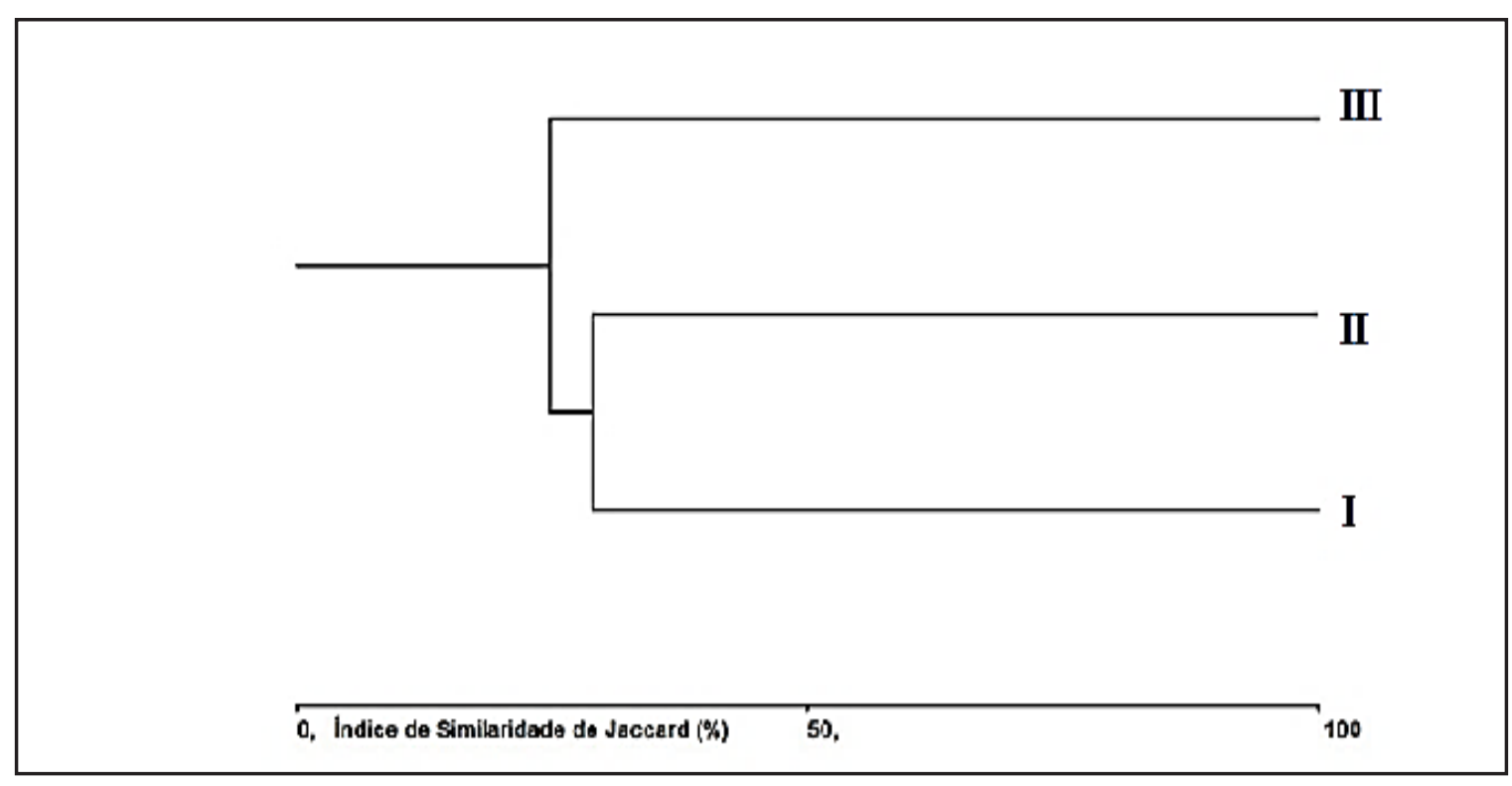

Fonte: Autores (2019)

Analisando a similaridade entre as áreas amostrais, verifica-se que o Fragmento I e o Fragmento || são os que menos diferem entre si, com similaridade média de 29\% (Figura 5). A similaridade entre o Fragmento III e os Fragmentos I e ll foi baixa, em média 
25\%. Uma possível explicação para isso pode residir no fato de que o Fragmento III, além do histórico de intervenção mais recente, foi no passado uma área de pastagem, sofrendo uma remoção severa da cobertura, o que leva a ser fisionomicamente distinta das demais.

Das 193 espécies encontradas nas três áreas, 24 foram comuns a todos os fragmentos, 17 exclusivas do Fragmento III, 36 exclusivas do Fragmento II e 68 exclusivas do Fragmento I. Portanto, apesar de caracterizarem o mesmo tipo fisionômico e sob a mesma região, os três fragmentos apresentam claras particularidades florísticas. Das 48 espécies encontradas no Fragmento I, 36,92\% são consideradas raras, no Fragmento II 49,48\% das 48 encontradas e no Fragmento III 40,32\% do total de 25 espécies. De acordo com Silva et al. (2015), podem ser consideradas espécies raras aquelas que apresentam até um indivíduo por hectare.

As espécies que apresentaram maiores Valores de Importância (VI) foram diferentes em cada fragmento (Figura 6), com exceção de Spondias mombin que além de ocorrer em todos os fragmentos e estratos apresentou significativo número de indivíduos comparada às demais espécies. Por se tratar de uma espécie com fruto altamente apreciado pela fauna local, a dispersão zoocórica pode ter influenciado a distribuição na área. Os indivíduos dessa espécie podem ser encontrados isolados ou agrupados, costumam se propagar por sementes ou se regenerar espontaneamente por estacas, obtendo sucesso de colonização em associação com outras espécies áreas de vegetação secundária ((SOUZA et al., 2000; VALE; COSTA; MIRANDA, 2014). A produção de pólen observada em Spondias mombin é abundante, sendo a polinização realizada por abelhas que são consideradas como excelentes polinizadoras pela rapidez e variedade de adaptações morfológicas para a coleta do pólen, sendo capazes de visitar um grande número de flores (MASCENA, 2011; CARNEIRO; MARTINS, 2012;)

De acordo com Grant (1981) e Stebbins (1950), o sucesso no mecanismo reprodutivo garante maior sucesso na colonização de espaços, constituindo um outro fator que pode ter facilitado a dispersão da espécie nas áreas analisadas. 
No Fragmento III foi observada elevada frequência de indivíduos de Attalea phalerata, fato relacionado ao histórico do uso de pastagem, o que pode ter contribuído para um menor índice de diversidade no fragmento. Inoue et al. (2013) afirmam que o desenvolvimento massivo dessa espécie em áreas de pasto pode convertê-las em plantas daninhas nesses locais por dificultarem o estabelecimento de outras espécies devido à competição.

Figura 6 - Formação do Índice de Valor de Importância (VI) para as dez espécies mais significativas por fragmento na APA Lago do Amapá em Rio Branco - AC

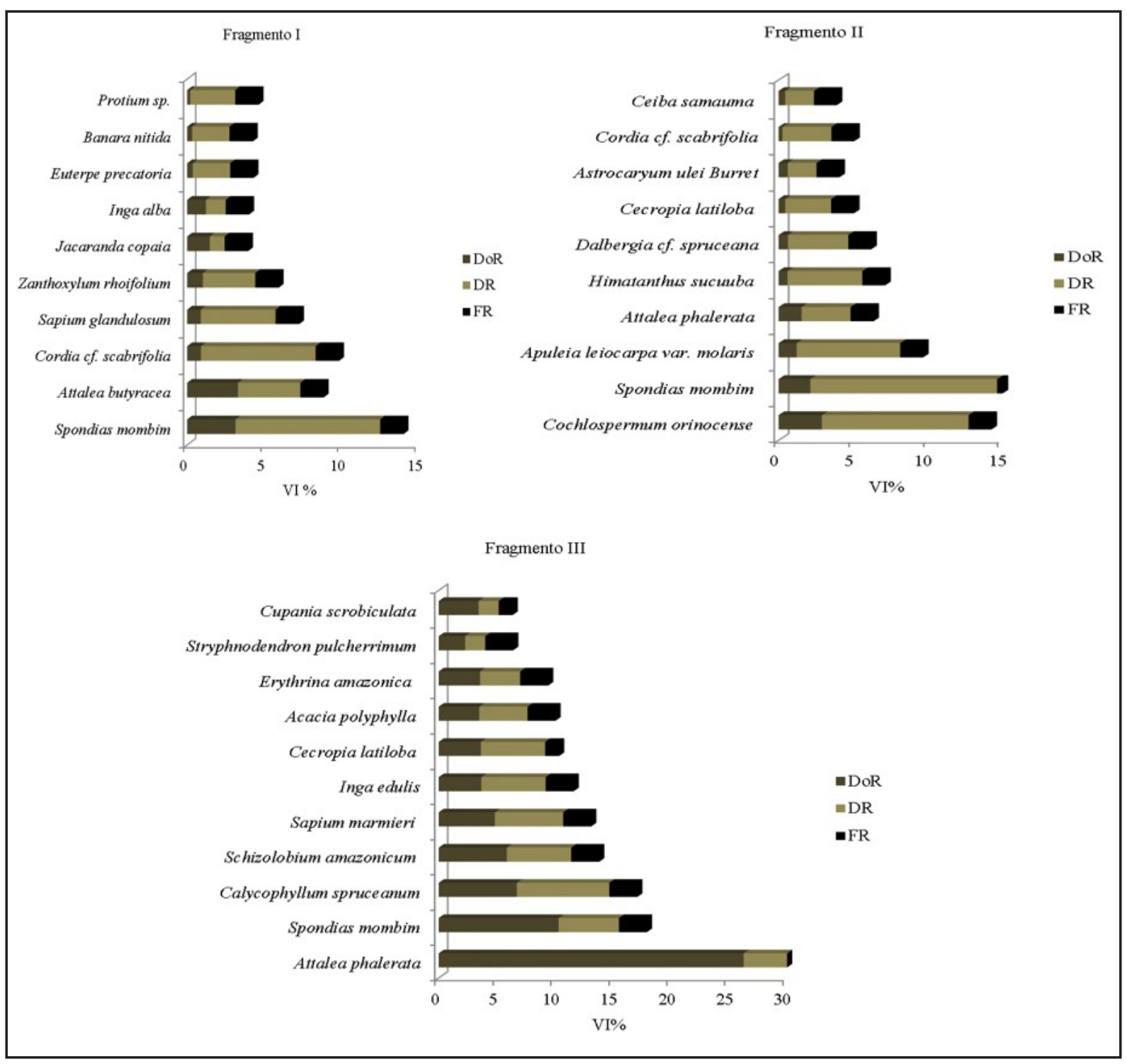

Fonte: Autores (2019) 
A estratificação indicou que, nos três fragmentos, a maior parte dos indivíduos se encontra no estrato médio (Tabela 2), com alturas inferiores a 16,23 m.O maior número de indivíduos evidencia que esse é o estrato dominante da vegetação (ARAÚJO, 2016).

Tabela 2 - Porcentagem de indivíduos por estrato em cada fragmento amostrado na APA Lago do Amapá em Rio Branco - AC

\begin{tabular}{lcccc}
\hline \multirow{3}{*}{ Estratos } & \multicolumn{3}{c}{ Estratos } \\
\cline { 2 - 3 } & Superior & Médio & & Inferior \\
\cline { 2 - 3 } & $\mathbf{h} \geq \mathbf{1 6 , 2 3}$ & $\mathbf{8 , 7 4} \leq \mathbf{h} \leq \mathbf{1 6 , 2 3}$ & $\mathbf{h}<\mathbf{8 , 7 4}$ \\
\hline I & 13,89 & 76,41 & 9,7 \\
II & 12,72 & 69,17 & 18,11 \\
III & 14,88 & 66,43 & \\
\hline
\end{tabular}

Fonte: Autores (2019)

Observou-se menor número de indivíduos no estrato inferior do Fragmento I comparado com os demais fragmentos, segundo Oliva et al. (2018), isso ocorre devido à menor abertura do dossel, sendo o fragmento mais antigo esse que concentrou mais indivíduos de grande porte e que competem por recursos, dificultando o estabelecimento dos de menor porte. As espécies Cordia cf. scabrifolia (43 indivíduos), Sapium glandulosum (26 indivíduos), Banara nitida (15 indivíduos), Zanthoxylum rhoifolium, Euterpe precatoria e Virola elongata (11 indivíduos cada) e Neea parviflora (10 indivíduos), também são mais numerosas no estrato médio. Attalea butyracea foi mais abundante no estrato inferior (13 indivíduos), seguida das espécies Protium sp. e Miconia sp. (6 indivíduos). no estrato superior destacaram-se as espécies Zanthoxylum rhoifolium (9 indivíduos) e Jacaranda copaia (6 indivíduos).

No Fragmento II, as espécies Cochlospermum orinocense (31 indivíduos), Spondias mombin (55 indivíduos), Apuleia leiocarpa (21 indivíduos), Himatanthus succuba (23 indivíduos), Cecropia latiloba (14 indivíduos) e Dalbergia cf. spruceana (13 indivíduos) foram mais numerosas no estrato médio. No estrato inferior, as mais numerosas 
foram Attalea phalerata (16 indivíduos) e Warszewiczia cf. coccinea (9 indivíduos.). Cochlospermum orinocense (17 indivíduos) e Apuleia leiocarpa (12 indivíduos) foram as mais numerosas no estrato superior.

No Fragmento III, a maior quantidade de espécies foi verificada no estrato médio. As espécies mais abundantes nesse estrato foram Spondias mombin (12 indivíduos), Calycophyllum spruceanum (13 indivíduos), Schizolobium amazonicum (9 indivíduos) e Sapium marmieri (12 indivíduos) apresentando maiores VI. No estrato inferior destacouse a espécie Attalea phalerata (29 indivíduos) e no superior Calycophyllum spruceanum (9 indivíduos).

A maior concentração de indivíduos no estrato médio pode ser devido à inclusão de apenas indivíduos com DAP $\geq 10 \mathrm{~cm}$. De acordo com Scolforo (1998), o critério de inclusão com DAP abaixo de $10 \mathrm{~cm}$ promove uma diminuição do número de indivíduos do estrato inferior para o superior. As espécies Calycophyllum spruceanum, Sapium marmieri, Erythrina amazonica, Triplaris weigeltiana e Spondias mombin foram encontradas em todos os estratos, ainda, segundo Scolforo (1998), quando isso ocorre significa que a participação dessas espécies na estrutura da floresta vai do início da sucessão até a fase clímax.

A distribuição em classes diamétricas por fragmento indicou que o maior número de indivíduos ocupou as menores classes (<15cm) (Figura 7), apresentando o padrão de distribuição J invertido, comum em florestas com dinâmica alta (DIONíSIO et al., 2016). De acordo com Diniz e Scudeller (2005), essa configuração de distribuição indica que a comunidade apresenta alto potencial de regeneração. O Fragmento I, como esperado, por ser o mais antigo, apresentou indivíduos distribuídos em mais classes diamétricas.

As diferenças significativas entre os números de indivíduos na primeira e na segunda classes diamétricas dos fragmentos analisados corrobora a informação de que as áreas de estudo já sofreram forte pressão por parte de atividades antrópicas, 
mas apresentam estoque em crescimento de espécies (LIMA et al., 2018). De acordo com Nunes et al. (2003), áreas que passaram por perturbações severas apresentam maior densidade de indivíduos de menores diâmetros e alturas, ao passo que áreas que passaram por distúrbios menos severos tendem a apresentar maior densidade de indivíduos de maiores diâmetros e alturas. O tempo decorrido entre as intervenções também é fator determinante para o incremento diamétrico, Oliva et al. (2018) afirmam que a área basal mais expressiva em áreas em estágios sucessionais mais antigos em relação às áreas de estágios recentes é comumente observada em ambientes florestais. A importância da distribuição dos indivíduos nas diferentes classes diamétricas é explicada por essa condição representar a garantia de permanência das diferentes espécies na estrutura dos fragmentos de floresta em estudo (BIANCHIN; BELLÉ, 2013).

Figura 7 - Distribuição diamétrica dos indivíduos dentro de cada fragmento amostrado na APA Lago do Amapá em Rio Branco - AC

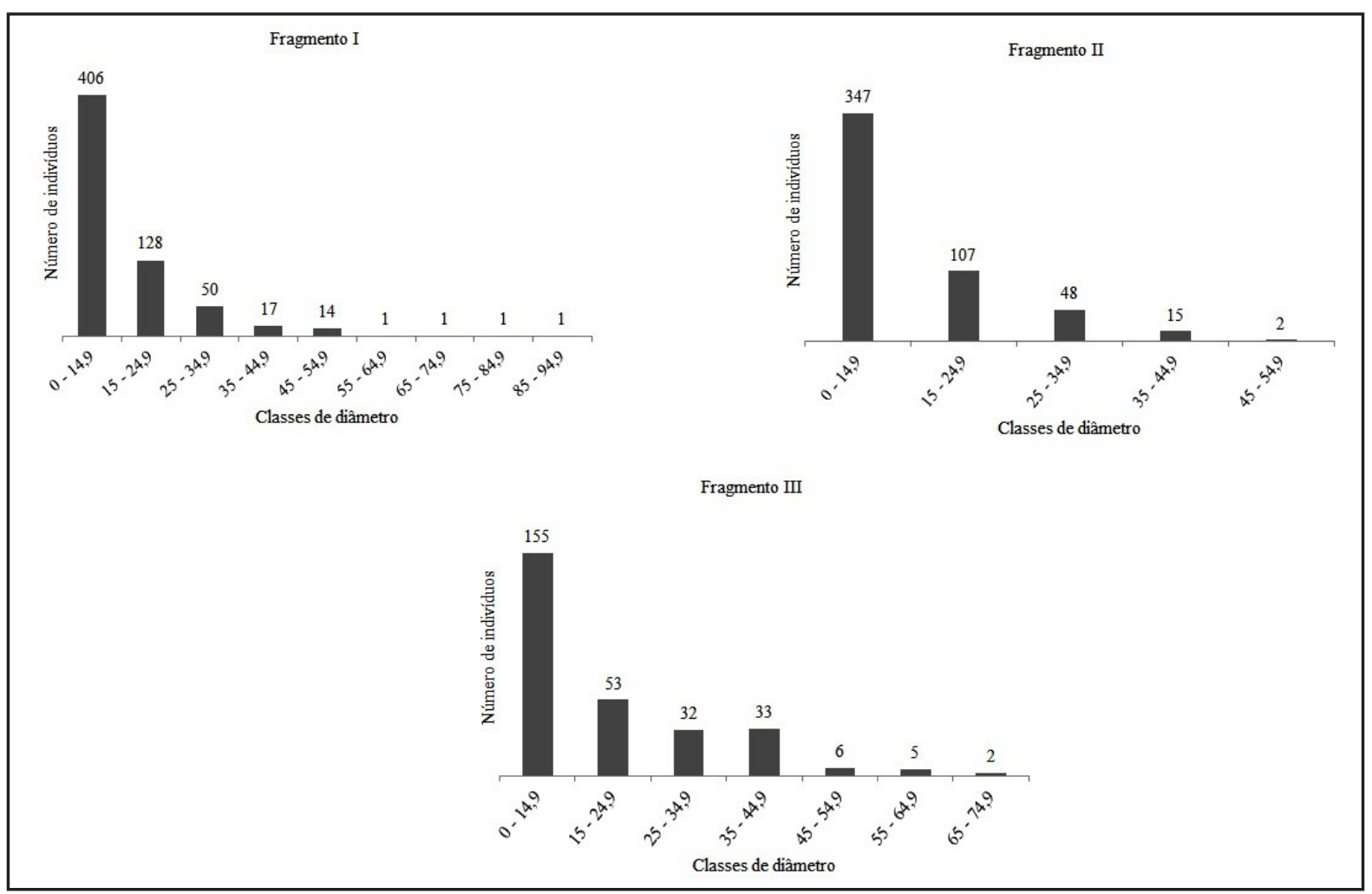

Fonte: Autores (2019) 


\section{CONCLUSÕES}

A composição florística das áreas avaliadas mostrou valores de diversidade de espécies aproximados aos encontrados em outros estudos na Amazônia, sendo o maior número de espécies e índice de diversidade registrados no Fragmento I, que se encontra em estágio mais avançado de regeneração.

Observou-se que a diversidade aumentou conforme a idade dos fragmentos. Os Fragmentos I e II apresentaram maior similaridade florística por possuírem históricos de intervenção antrópica mais antigos. Há predominância de indivíduos jovens nos três fragmentos analisados, demonstrando a alta atividade do processo de regeneração após as intervenções sofridas. Concluiu-se que houve diferença nos parâmetros florísticos e estruturais entre os três fragmentos florestais em função da cronologia de antropização.

\section{AGRADECIMENTOS}

Ao professor Dr. Edmilson Santos Cruz pelo auxílio na definição da metodologia e análise de dados e aos colegas Cleison Cavalcante de Mendonça e Ednéia Araújo dos Santos pela ajuda em campo.

\section{REFERÊNCIAS}

ACRE. Secretaria de Estado de Meio Ambiente. Peça de criação da Área de Proteção Ambiental (APA) Lago do Amapá, Unidade de conservação de uso sustentável. Rio Branco, 2005.

ACRE. Secretaria de Estado de Meio Ambiente. Programa Estadual de Zoneamento EcológicoEconômico do Estado do Acre. Documento Síntese. Rio Branco, 2010.

ANGIOSPERM PHYLOGENY GROUP III. An update of the Angiosperm Phylogeny Group classification for the orders and families of flowering plants: APG III. Botanical Journal of the Linnean Society, London, v. 161, n. 2, p. 105-121, 2009.

ANDRADE, D. F. et al. Inventário florestal de grandes áreas na Floresta Nacional do Tapajós, Pará, Amazônia, Brasil. Biota Amazônia, Macapá, v. 5, n. 1, p. 109-115, 2015.

ARAÚJO, E. D. S. Identificação de ilhas de calor na cidade de Campina Grande-PB utilizando sensoriamento remoto. Revista Brasileira de Geografia Física, Recife, v. 9, n. 2, p. 614-626, 2016. 
AMARAL, D. D.; VIEIRA, I. C. G.; ALMEIDA, S. S. Características ecológicas e estrutura da comunidade arbórea de um remanescente florestal na área de endemismo Belém. Revista Brasileira de Biosciências, Porto Alegre, v. 14, n. 4, p. 225-232, 2016.

BIANCHIN, J. E.; BELLÉ, P. A. Fitossociologia e estrutura de um fragmento de floresta estacional decidual aluvial em Santa Maria - RS. Revista Agro@mbiente, Boa Vista, v. 7, n. 3, p. 322-330, 2013.

CARIM, M. J. V. et al. Composição e estrutura de floresta ombrófila densa do extremo norte do estado do Amapá, Brasil. Biota Amazônia, Macapá, v. 3, p. 1-10, 2013.

CARNEIRO, L. T.; MARTINS, C. F. Africanized honey bees pollinate and preempt the polen of Spondias mombin (Anacardiaceae) flowers. Apidologie, LesUlis, v. 43, n. 4, p. 474-486, 2012.

CONDÉ, T. M.; TONINI, H. Fitossociologia de uma floresta ombrófia densa na Amazônia Setentrional, Roraima, Brasil. Acta Amazonica, Manaus, v. 43, n. 3, p. 247-260, 2013.

DINIZ, K. S.; SCUDELLER, V. V. Estrutura fitossociológica de uma floresta de terra firme na Amazônia Central. Biotupe: Meio físico, Diversidade Biológica e Sociocultural do Baixo Rio Negro, Amazônia Central; Manaus: INPA, 2005. p. 155-168.

DIONÍSIO, L. F. S. et al. Importância fitossociológica de um fragmento de floresta ombrófila densa no estado de Roraima, Brasil. Revista Agro@mbiente, Boa Vista, v. 10, n. 3, p. 243-252, 2016.

GRANT, V. Plant Speciation. New York: Columbia University Press, 1981. 563 p.

GONÇALVES, F. G.; SANTOS, J. R. Composição florística e estrutura de uma unidade de manejo florestal sustentável na Floresta Nacional do Tapajós, Pará. Acta Amazonica, Manaus, v. 38, n. 2, p. 229-244, 2008.

GOMES, J. M.; GONÇALVES, F. G.; SANTOS, J. R. Sobrevivência de espécies arbóreas plantadas em clareiras causadas pela colheita de madeira em uma floresta de terra firme no município de Paragominas na Amazônia Brasileira. Acta Amazonica, Manaus, v. 40, n. 1, p. 171-178, 2010.

INOUE, M. H. et al. Levantamento fitossociológico de plantas daninhas em pastagens no município de Nova Olímpia - MT. Revista Agrarian, Dourados, v. 6, n. 22, p. 376-384, 2013.

INSTITUTO DE PESQUISAS ESPACIAIS (Brasil). INPE divulga dados de degradação da Amazônia. Brasília, 2019. Disponível em: www.inpe.br/noticia/noticia.php?Cod_Noticia=3687. Acessado em: 30 jun. 2019.

LIMA, H. C. de et al. Fabaceae. In: JARDIM BOTÂNICO DO RIO DE JANEIRO. Lista de Espécies da Flora do Brasil. Rio de Janeiro, 2019. Disponível em: http://floradobrasil.jbrj.gov.br/2012/ FB000115. Acesso em: 03 jul. 2019.

LIMA, R. B. A. et al. Análises estruturais do componente arbóreo em floresta de terra firme, Carauari, Amazonas, Brasil. Biodiversidade, Cuiabá, v. 17, n. 1, p. 2-16, 2018.

MASCENA, V. M. Abelhas visitantes florais, potenciais polinizadores do algodoeiro (Gossypium hirsutum L.) em cultivo agroecológico. 2011. Dissertação (Mestrado em Zootecnia) - Universidade Federal do Ceará, Fortaleza, 2011. 
MOURA, V.; ROSSELL, C. D.; MASCARENHAS, A. R. P. Análise fitossociológica de uma floresta ombrófila aberta em diferentes modelos de colonização na Amazônia. Nativa, Sinop, v. 8, n. 2, p. 118-126, 2017.

NUNES, Y. R. et al. Variações da fisionomia, diversidade e composição de guildas da comunidade arbórea em um fragmento de floresta semidecidual em lavras, MG. Acta Botanica Brasilica, Belo Horizonte, v. 17, n. 2, p. 213-229, 2003.

OLIVA, E. V. et al. Florística e estrutura de duas comunidades arbóreas secundárias com diferentes graus de distúrbio em processo de recuperação. Ciência Florestal, Santa Maria, v. 28, n. 3, p. 1088-1103, 2018.

OLIVEIRA, A. N.; AMARAL, I. L. Aspectos floriśiticos, fitossociológicos e ecológicos de um subbosque de terra firme na Amazônia Central, Amazonas, Brasil. Acta Amazonica, Manaus, v. 35, n. 1, p. 1-16, 2005.

PARTHANSARATHY, N. Treediversity anda distribuition in undisturbed and humanimpactedsites of tropical wetevergreenforest in southern Western Ghats, India. Biodiversit and Conservation, Dordrecht, v. 8, n. 4, p. 1365-1381, 1999.

PRADO, D. A.; MALLMANN, C. L.; PEREIRA FILHO, W. Índice de vegetação por diferença normalizada para a caracterização da dinâmica florestal no Parque Estadual Quarta Colônia, estado do Rio Grande do Sul - Brasil. Revista Brasileira de Geografia Física, Recife, v. 8, n. 5, p. 1454-149, 2015.

SCOLFORO, J. R. Manejo florestal. In: SCOLFORO, J. R.; PULZ, F. A.; MELO, J. M. de. (ed.). Modelagem da produção, idade das florestas nativas, distribuição espacial das espécies e a análise estrutural. Lavras: UFLA; FAEPE, 1998. p. 89-246.

SILVA, K. E. et al. Dinâmica florestal, estoque de carbono e fitossociologia de uma floresta densa de terra-firme na Amazônia Central. Scientia Forestalis, Piracicaba, v. 43, n. 105, p. 193-201, 2015.

SILVA, W. A. S. et al. Composição e diversidade florística em um trecho de floresta de terra firme no sudoeste do estado do Amapá, Amazônia Oriental, Brasil. Biota Amazônia, Macapá, v. 4, n. 3, p. 31-36, 2014.

SOUSA, D. A. S.; APARÍCIO, W. C. S. Diversidade e similaridade florística em áreas sob influência de uma usina hidrelétrica na Amazônia. Revista em Agronegócio e Meio Ambiente, Maringá, v. 11, n. 4, p. 1195-1216, 2018.

SOUZA, A. L. Mata Nativa 2: sistema para a análise fitossociológica e elaboração de planos de manejo de florestas nativas. Viçosa, MG: CIENTEC - Consultoria de Desenvolvimento de Sistemas, 2006. 295 p.

SOUZA, A. L.; LEITE, H. G. Regulação da produção em florestas inequiâneas. Viçosa, MG: UFV, 1993. 147 p.

SOUZA, F. X. de et al. Aspectos morfológicos da unidade de dispersão de cajazeira. Pesquisa Agropecuária Brasileira, Brasília, v. 35, n. 1, p. 215-220, 2000.

STEBBINS G. L. Variation and Evolution in Plants. New York: Columbia University Press, 1950. $644 \mathrm{p}$. 
TER STEEGE, H. et al. Hyperdominance in the Amazonian Tree Flora. Science, Washington, DC, v. 342, n. 615, p. 342-352, 2013.

VALE, I.; COSTA, L. G. S.; MIRANDA, I. S. Espécies indicadas para a recomposição da floresta ciliar da sub-bacia do rio peixe-boi, Pará. Ciência Florestal, Santa Maria, v. 24, n. 3, p. 573-582, 2014.

VERÍSSIMO, A. A. et al. Áreas protegidas na Amazônia Brasileira: avanços e desafios. Belém, PA: Imazon, 2011. 87 p.

\section{Contribuição de Autoria}

\section{1 - Simone Pereira da Silva}

Engenheira Florestal, Esp.

https://orcid.org/0000-0002-6925-5859•simone.psm@gmail.com

Contribuição: Conceituação, Metodologia, Investigação, Curadoria de dados, Análise formal, Visualização, Escrita - primeira redação, Escrita - revisão e edição

\section{2 - Evandro José Linhares Ferreira}

Engenheiro Agrônomo, Pesquisador

https://orcid.org/0000-0001-9591-9615•evandroferreira@hotmail.com.br

Contribuição: Conceitualização, Obtenção de financiamento, Administração do projeto, Recursos, Supervisão, Análise formal, Validação, Visualização, Escrita - primeira redação, Escrita - revisão e edição

\section{3 - Lucélia Rodrigues Santos}

Engenheira Florestal, Ma., Professora

https://orcid.org/0000-0002-8897-4701•santos.luceliarodrigues@gmail.com

Contribuição: Investigação, Curadoria de dados, Visualização, Escrita - primeira redação, Escrita - revisão e edição

\section{Como citar este artigo}

Silva, S. P.; Ferreira, E. J. L.; Santos, L. R. Fitossociologia e diversidade em fragmentos florestais com diferentes históricos de intervenção na Amazônia Ocidental. Ciência Florestal, Santa Maria, v. 31, n. 1, p. 233-251, 2021. DOI 10.5902/1980509839027. Disponível em: https://doi. org/10.5902/1980509839027. Acesso em: xx mês abreviado 202x. 